Génét. Sél. Evol., 1984, 16 (3), 355-366

\title{
Croissance et efficacité alimentaire de poulets "Cou nu " ou normalement emplumés selon la teneur en protéines de la ration
}

\author{
A. ZEIN-EL-DEIN (1), A. BORDAS et P. MÉRAT \\ I.N.R.A., Laboratoire de Génétique factorielle, \\ Centre de Recherches zootechniques, F 78350 Jouy-en-Josas
}

\begin{abstract}
Résumé
La croissance pondérale et l'efficacité alimentaire jusqu'à 10 semaines d'âge ont été comparées pour des poulets "Cou nu » hétérozytes $\left(\mathrm{Na} \mathrm{na}^{+}\right)$et des oiseaux normalement emplumés (na ${ }^{+}$ $\mathrm{na}^{+}$) issus des mêmes familles. Les 2 sexes étaient traités indépendamment, les mâles étant élevés en cages individuelles à $29 \% \mathrm{C}$, après 4 semaines, les femelles $\mid$ au sol entre $\mid 23$ et $24 ; \circ \mid \mathrm{C}$. $\mid$ Chaque génotype était réparti dans 2 groupes, recevant respectivement une ration à 16 et 20 p. 100 de protéines totales. Enfin, sur un groupe séparé de mâles répartis selon les 2 types d'aliment le plumage était mesuré en proportion du poids vif de 2 en 2 semaines.

Pour les mâles en cages individuelles, le seul effet global significatif associé au génotype concerne l'efficacité alimentaire (aliment consommé/gain de poids) de 6 à 8 semaines, à l'avantage des poulets "Cou nu ». Chez les femelles, un avantage d'ensemble du même génotype existe pour le gain de poids de 4 à 6 semaines. En outre, des interactions entre génotype et taux protéique sont hautement significatives chez les femelles, pour les poids corporels à 8 et 10 semaines et le gain de poids de 6 à 8 semaines; pour ces 3 variables, la performance des femelles $\mathrm{Na} \mathrm{na}^{+}$est la meilleure en présence de la ration à $16 \mathrm{p}$. 100 de protéines, et la moins bonne avec le taux de 20 p. 100. De plus, chez les mâles, bien que les effets ne soient pas significatifs, à partir de 6 semaines d'âge, toutes les différences suggèrent un avantage des oiseaux « Cou nu » sur les autres en présence de l'aliment le moins riche en protéines. Le poids relatif du plumage montre une interaction entre âge et type de ration : son développement paraît hâté à partir de 4 semaines avec le taux protéique le plus élevé. La réduction du plumage produite par le gène $\mathrm{Na}$ est indépendante, quant à elle, du taux protéique. L'effet propre de la composition du régime est apparent sur l'efficacité alimentaire, améliorée par le taux protéique le plus élevé, qui d'autre part abaisse le taux plasmatique d'acide urique mesuré chez les femelles.
\end{abstract}

Mots clés : Gène Cou nu, croissance, indice de consommation, taux protéique.

\section{Summary}

Growth and feed efficiency of "Naked neck" vs normally feathered chicks according to protein level ot the ration

Growth rate and feed efficiency up to 10 weeks of age were compared for heterozygous naked neck birds $\left(\mathrm{Na} \mathrm{na}^{+}\right)$and their normally feathered full - or half-sibs $\left(\mathrm{na}^{+} \mathrm{na}^{+}\right)$. The 2 sexes were

(1) Adresse permanente : Département de Production animale. Faculté d'Agriculture, Université AïnShams, Le Caire, Egypte. 
treated independently, males being kept in individual cages at $29^{\circ} \mathrm{C}$ from 4 weeks, females in floor pens between 23 and $24^{\circ} \mathrm{C}$ (average). Each genotype was distributed into 2 groups, receiving respectively a ration with 16 and 20 p. 100 total protein. Other male chicks were used separately for measuring plumage as a proportion of live body weight at 2 -week intervals with each of the 2 rations.

For males in cages, the only significant genotype effect is on feed efficiency from 6 to 8 weeks, at the advantage of naked neck chicks. In females, an overall advantage of $\mathrm{Na} \mathrm{na}^{+}$birds for weight gain from 4 to 6 weeks appears. Besides this, genotype $x$ protein level interactions are highly significant among females for 8 and 10 week body weights, and weight gain from 6 to 8 weeks ; in these cases the performance of $\mathrm{Na} \mathrm{na}{ }^{+}$females is higher than that of na ${ }^{+} \mathrm{na}^{+}$birds with the 16 p. 100 protein level, the reverse being obtained with the 20 p. 100 protein ration. In addition, in males, although differences are not significant, from 6 weeks of age all suggest an advantage of naked neck chicks in presence of the poorer protein level. The relative weight of the plumage shows an age $x$ protein level interaction : relative growth of feathers is increased after 4 weeks of age by the 20 p. 100 protein feed. The reduction of plumage by the Na gene shows no interaction with feed composition. The effect of ration formula is apparent on feed efficiency, which is improved by the higher protein level, and on uric acid in plasma (measured in females), which is lower with this type of ration.

Key words : Naked neck gene, growth, feed efficiency, protein level.

\section{Introduction}

Le gène autosomal «Cou nu » $(\mathrm{Na})$ a été identifié depuis longtemps chez la poule domestique (HuTT, 1949). Il réduit l'extension des ptérylies, en particulier dans la région du cou, avec dominance incomplète (CRAwFORD, 1976 ; SCOTT \& CRAWFORD, 1977). Par suite de cette réduction du plumage, il paraissait intéressant de comparer le comportement physiologique et les performances des génotypes " Cou nu » $\left(\mathrm{Na} \mathrm{Na}\right.$ ou $\mathrm{Na} \mathrm{na}^{+}$) et normal $\left(\mathrm{na}^{+} \mathrm{na}^{+}\right)$selon la température ambiante. SMITH \& LEE (1977) observent moins de mortalité parmi des poussins «Cou nu » hétérozygotes que pour des poussins à plumage normal en réponse à une température élevée. Concernant la croissance, le gène "Cou nu » à l'état hétérozygote s'accompagne à température modérée d'une très légère diminution du poids corporel des mâles à 8 semaines d'âge, qui peut correspondre à la seule réduction du plumage (MÉRAT, 1979). Par contre, à une température maintenue au-dessus de $30^{\circ} \mathrm{C}$ jusqu'à 10 semaines, le gène $\mathrm{Na}$ à l'état homozygote ou hétérozygote a été trouvé associé à un avantage de croissance de l'ordre de 10 p. 100 par BORDAS et al. (1978), MONNET et al. (1979), HANZL \& SOMES (1983) ; dans ces conditions, l'indice de consommation n'était pas significativement modifié mais semblait légèrement amélioré par l'allèle $\mathrm{Na}$. Entre les mêmes génotypes soumis après l'âge de 4 semaines à une température moyenne comprise entre 15 et $20^{\circ} \mathrm{C}$, il n'y avait pas de différence significative de croissance pondérale, mais l'efficacité alimentaire était moins bonne pour le génotype $\mathrm{Na} \mathrm{na}+$ et surtout $\mathrm{Na} \mathrm{Na}$. Cet effet différentiel de la température ambiante explique probablement l'avantage relatif de croissance observé par ZEIN-EL-DEIN et al. (1981) à la saison chaude en Egypte pour des poulets "Cou nu " hétérozygotes comparés à des poulets à plumage normal dans un croisement d'une lignée Fayoumi, alors qu'en hiver aucune différence significative n'apparaissait.

Ces résultats suggèrent l'intérêt du gène $\mathrm{Na}$ dans des conditions climatiques relativement chaudes. Nous avons donc voulu préciser les conditions optimales d'une utilisation éventuelle d'animaux porteurs de ce gène, en particulier du point de vue du taux 
protéique de la ration. Le poids total du plumage est, en effet, réduit respectivement d'environ 30 et 40 p. 100 pour les oiseaux $\mathrm{Na} \mathrm{na+}$ et $\mathrm{Na} \mathrm{Na}$ comparés au génotype normal (BordAs et al., 1978 ; MONNET et al., 1979) ; la matière sèche des plumes étant principalement composée de protéines, cette réduction peut représenter une économie du besoin azoté durant la période de pousse maximale du plumage. D'autre part, les animaux «Cou nu», consommant davantage d'aliment pour leur besoin énergétique, ingèrent la même quantité de protéines que les poussins normaux pour un taux protéique plus faible dans la ration.

\section{Matériel et méthodes}

\section{A. Animaux}

Les poussins expérimentaux sont issus de l'insémination pédigree de poules hétérozygotes $\mathrm{Na} \mathrm{na}^{+}$par des reproducteurs mâles entièrement emplumés (na+ na+ ${ }^{+}$: au total 9 pères et 5 mères par père. Ces poussins sont éclos le 29-10-1982. A l'éclosion, le sexe et le génotype ( $\mathrm{Na} \mathrm{na}^{+}$ou $\mathrm{na}^{+} \mathrm{na}^{+}$) étaient déterminés et chaque individu bagué.

\section{B. Conditions expérimentales}

La période expérimentale s'étendait jusqu'à l'âge de 10 semaines. A 1 jour, les poussins étaient mis au sol, avec une température initiale sous éleveuse voisine de $35^{\circ} \mathrm{C}$. Les 2 sexes étaient traités de façon séparée. Les femelles étaient élevées au sol jusqu'à la fin de l'expérience. La température sous éleveuse diminuait graduellement jusqu'à l'âge de 4 semaines, puis la température moyenne réalisée entre 4 et 10 semaines était comprise entre 23 et $24^{\circ} \mathrm{C}$, avec des extrêmes de 18 et $29^{\circ} \mathrm{C}$. Quant aux mâles, 120 d'entre eux choisis au hasard dans les familles les plus nombreuses étaient gardés et placés en cages individuelles dans un local maintenu constamment à $29 \pm 1^{\circ} \mathrm{C}$. Tous les poussins recevaient par jour $10 \mathrm{~h}$ de lumière, de $8 \mathrm{~h}$ à $18 \mathrm{~h}$.

Dans les 2 sexes, chaque génotype était réparti par moitié en 2 lots, recevant respectivement une ration à 16 et 20 p. 100 de protéines totales. Pour les femelles, 2 loges identiques de poussinière étaient utilisées, une par régime, et dans chacune les 2 génotypes étaient séparés par une cloison grillagée ; ceci permettait d'obtenir l'indice de consommation global de chaque sous groupe. Pour les mâles, les 2 régimes étaient répartis également parmi les 2 génotypes et pour les 3 étages de la batterie. Les 2 rations avaient la même teneur en énergie métabolisable (environ $2900 \mathrm{kcal} / \mathrm{kg}$ ). Le tableau 1 donne la composition de chacune. Les 2 aliments étaient distribués ad libitum de l'âge de 3 jours à la fin de l'expérience.

Enfin, dans une batterie collective de 4 étages située dans le même local que les cages individuelles, 64 coquelets étaient élevés avec distribution des 2 génotypes dans chaque étage et alternance des 2 régimes selon l'étage, et 16 d'entre eux (4 par régime et génotype) étaient prélevés au hasard aux âges respectifs de $4,6,8$ et 10 semaines, pour détermination du poids du plumage rapporté au poids corporel. 


\section{TABleau 1}

Composition des régimes.

Feed composition.

\begin{tabular}{|c|c|c|}
\hline \multirow{2}{*}{ Composants } & \multicolumn{2}{|c|}{ P. 100 du total } \\
\hline & Régime 1 & Régime 2 \\
\hline Blé & 40,00 & 40,00 \\
\hline 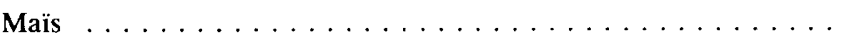 & 39,40 & 33,50 \\
\hline Tourteau soja $50 \% \ldots \ldots \ldots \ldots \ldots \ldots \ldots \ldots \ldots$ & 10,90 & 16,24 \\
\hline Farine luzerne $\ldots \ldots \ldots \ldots \ldots \ldots \ldots \ldots \ldots \ldots \ldots \ldots \ldots \ldots \ldots$ & 1,10 & - \\
\hline Farine viande $50 \% \ldots \ldots \ldots \ldots \ldots \ldots \ldots \ldots$ & 5,50 & 8,00 \\
\hline 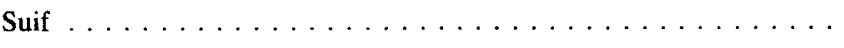 & - & 0,30 \\
\hline 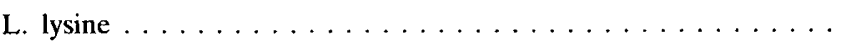 & 0,182 & - \\
\hline D.L. méthionine $\ldots \ldots \ldots \ldots \ldots \ldots \ldots \ldots \ldots \ldots \ldots \ldots \ldots \ldots \ldots$ & - & 0,098 \\
\hline Complément minéral et vitaminique $\ldots \ldots \ldots \ldots \ldots \ldots \ldots$ & 2,91 & 1,86 \\
\hline \multicolumn{3}{|l|}{ Principales caractéristiques : } \\
\hline Protéines totales, $\% \ldots \ldots \ldots \ldots \ldots \ldots \ldots$ & 16,0 & 20,0 \\
\hline Energie métabolisable, $\mathrm{Kcal} / \mathrm{kg} \ldots \ldots \ldots \ldots$ & 2900 & 2900 \\
\hline 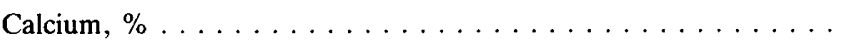 & 1,0 & 1,0 \\
\hline Phosphore total, $\% \ldots \ldots \ldots \ldots \ldots \ldots \ldots \ldots$ & 0,6 & 0,6 \\
\hline
\end{tabular}

\section{Mesures}

Dans les 2 sexes, chaque individu était pesé à 1 jour, puis de 2 en 2 semaines, et les gains de poids correspondants en étaient déduits.

La consommation alimentaire était enregistrée, collectivement pour chaque génotype chez les femelles, et individuellement pour les mâles, de 2 en 2 semaines également, et l'indice de consommation (rapport de l'aliment consommé au gain de poids) en était déduit.

Le taux d'acide urique plasmatique était déterminé à 10 semaines sur un échantillon de $60 \varsubsetneqq$ au total par un analyseur semi-automatique Beckman, à partir d'une prise de sang faite entre 9 et $11 \mathrm{~h}$ (poulettes à jeun depuis la veille au soir).

\section{Analyses statistiques}

Du fait des conditions différentes d'élevage, les données ont été traitées séparément dans chaque sexe, par une analyse de variance à 3 facteurs (génotype, régime, famille de père). Subsidiairement, une analyse de variance à 1 facteur (génotype) a été faite à l'intérieur de chaque sexe et régime. Le détail n'en est pas présenté, mais les différences significatives correspondantes sont mentionnées dans la partie "Résultats ». 
Chez les femelles, l'indice de consommation ne peut être étudié statistiquement et n'est donné qu'à titre indicatif. Dans ce sexe, d'autre part, l'absence de répétition ne permet pas de séparer un éventuel effet «loge de poussinière » de l'effet " régime ".

\section{Résultats}

Les tableaux 2 et 4 montrent les performances moyennes de croissance et d'efficacité alimentaire suivant le génotype et le régime, respectivement pour les poussins mâles et femelles. Les analyses de variance correspondantes sont contenues dans les tableaux 3 et 5 .

\section{TABLEAU 2}

Poussins mâles: Performances moyennes suivant le génotype et le régime.

Male chicks : Mean performance according to genotype at Na locus and feed composition.

\begin{tabular}{|c|c|c|c|c|c|c|c|c|}
\hline \multirow{3}{*}{ Caractère } & \multicolumn{8}{|c|}{ Valeurs moyennes } \\
\hline & \multicolumn{2}{|c|}{$\begin{array}{c}\text { Régime } 1 \\
\text { (16 \% prot.) }\end{array}$} & \multicolumn{2}{|c|}{$\begin{array}{c}\text { Régime } 2 \\
(20 \% \text { prot. })\end{array}$} & \multicolumn{2}{|c|}{ Total } & \multicolumn{2}{|c|}{ Total } \\
\hline & $\begin{array}{l}\mathrm{Na} \mathrm{na}^{+} \\
(\mathrm{n}=28)\end{array}$ & $\begin{array}{l}n a^{+} n a^{+} \\
(n=26)\end{array}$ & $\begin{array}{l}\mathrm{Na} \mathrm{na}^{+} \\
(\mathrm{n}=27)\end{array}$ & $\begin{array}{l}\mathrm{na}^{+} \mathrm{na}^{+} \\
(\mathrm{n}=27)\end{array}$ & $\mathrm{Na} \mathrm{na}^{+}$ & $\mathrm{na}^{+} \mathrm{na}^{+}$ & $\begin{array}{c}\text { Régime } \\
1\end{array}$ & $\begin{array}{l}\text { Régime } \\
2\end{array}$ \\
\hline \multicolumn{9}{|l|}{ Poids corporel $(\mathrm{g})$ : } \\
\hline $1 \mathrm{j} . \ldots \ldots \ldots$ & 37,8 & 37,9 & 39,5 & 38,6 & 38,6 & 38,3 & 37,8 & 39,1 \\
\hline 2 s. $\ldots \ldots \ldots \ldots$ & 114,1 & 115,7 & 113,4 & 113,4 & 114,3 & 114,5 & 114,9 & 114,0 \\
\hline 4 s. $\ldots \ldots \ldots \ldots$ & 336,9 & 339,6 & 330,9 & 338,3 & 333,9 & 338,9 & 338,2 & 334,6 \\
\hline 6 s. $\ldots \ldots \ldots \ldots$ & 682,0 & 694,7 & 679,4 & 708,9 & 680,7 & 686,6 & 687,9 & 693,9 \\
\hline $8 \mathrm{~s} . \ldots \ldots \ldots$ & 1069,3 & 1017,2 & 1070,2 & 1074,7 & 1069,8 & 1043,7 & 1043,3 & 1072,4 \\
\hline $10 \mathrm{~s} . \ldots \ldots \ldots$ & 1458,4 & 1397,3 & 1484,3 & 1464,8 & 1471,1 & 1441,6 & 1429,0 & 1474,6 \\
\hline \multicolumn{9}{|l|}{ Gain de poids $(g)$ : } \\
\hline $2-4$ s. $\ldots \ldots \ldots$ & 222,8 & 223,8 & 216,4 & 224,9 & 219,6 & 224,4 & 223,3 & 220,4 \\
\hline 4- $6 \mathrm{~s} . \ldots \ldots$ & 343,9 & 345,1 & 347,3 & 366,2 & 345,6 & 356,1 & 344,5 & 356,6 \\
\hline 6- 8 s. $\ldots \ldots \ldots$ & 413,5 & 389,4 & 424,2 & 405,2 & 418,9 & 397,5 & 402,0 & 415,1 \\
\hline $8-10$ s. $\ldots \ldots \ldots$ & 392,7 & 373,4 & 410,4 & 390,7 & 401,4 & 382,2 & 383,4 & 400,6 \\
\hline \multicolumn{9}{|l|}{$\begin{array}{l}\text { Indice } \\
\text { de consommation } \\
\text { (consommation/ } \\
\text { gain de poids) : }\end{array}$} \\
\hline $2-4$ s. $\ldots \ldots$ & 2,19 & 2,21 & 2,08 & 2,06 & 2,14 & 2,13 & 2,20 & 2,07 \\
\hline 4- $6 \mathrm{~s} . \ldots \ldots \ldots$ & 2,46 & 2,46 & 2,33 & 2,33 & 2,40 & 2,39 & 2,46 & 2,33 \\
\hline 6- 8 s. $\ldots \ldots \ldots$ & 2,75 & 2,91 & 2,59 & 2,73 & 2,67 & 2,82 & 2,83 & 2,66 \\
\hline $8-10$ s. $\ldots \ldots \ldots$ & 3,32 & 3,52 & 3,19 & 3,56 & 3,26 & 3,54 & 3,42 & 3,38 \\
\hline Total $2-10 \mathrm{~s}$. & 2,71 & 2,77 & 2,53 & 2,63 & 2,62 & 2,70 & 2,74 & 2,58 \\
\hline
\end{tabular}




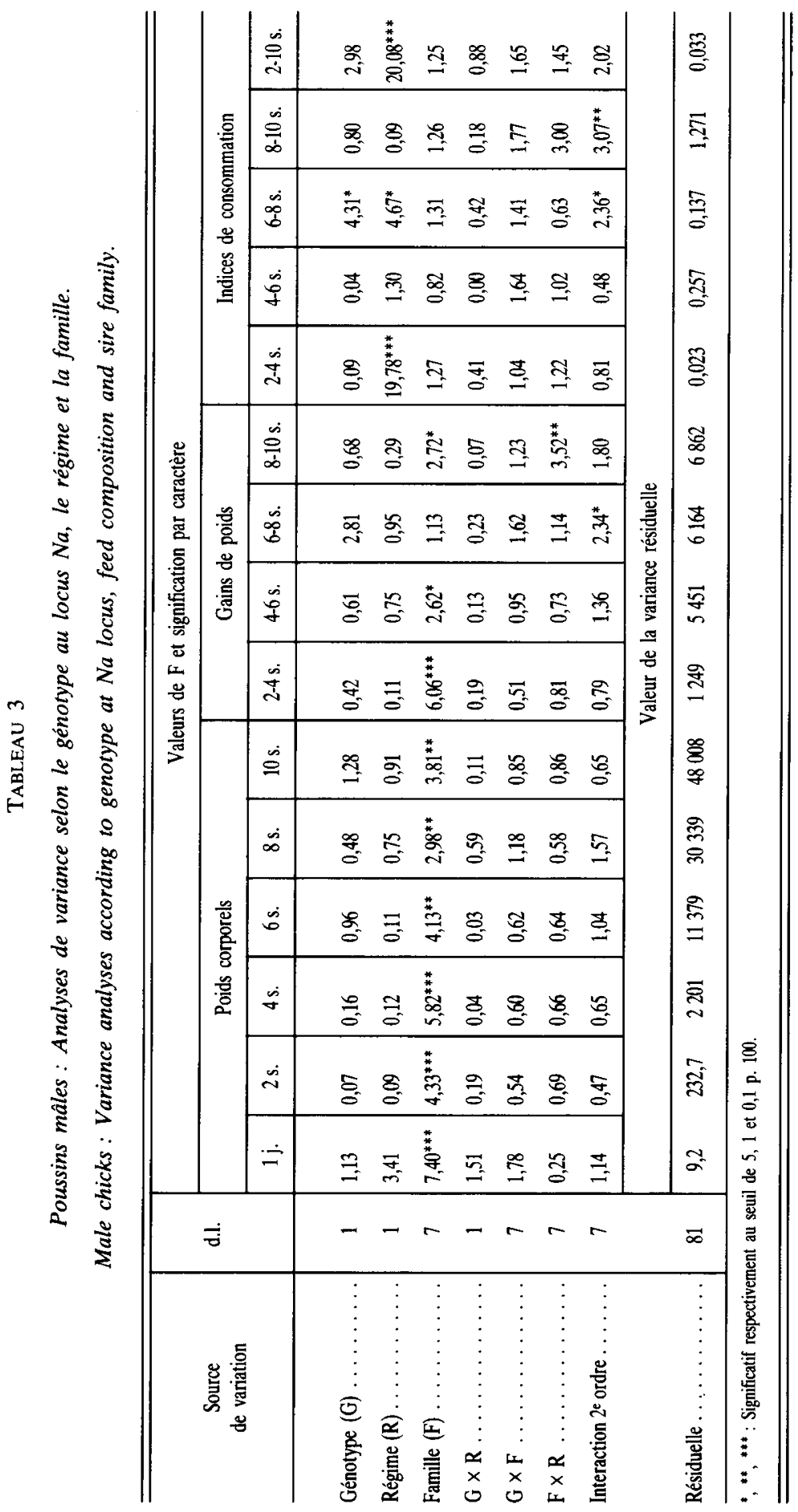


TABLEAU 4

Poussins femelles: Performances moyennes suivant le génotype et le régime.

Female chicks : Mean performance according to genotype at Na locus and feed composition.

\begin{tabular}{|c|c|c|c|c|c|c|c|c|}
\hline \multirow{3}{*}{ Caractère } & \multicolumn{8}{|c|}{ Valeurs moyennes } \\
\hline & \multicolumn{2}{|c|}{$\begin{array}{c}\text { Régime } 1 \\
\text { (16\% prot.) }\end{array}$} & \multicolumn{2}{|c|}{$\begin{array}{c}\text { Régime } 2 \\
(20 \% \text { prot. })\end{array}$} & \multicolumn{2}{|c|}{ Total } & \multicolumn{2}{|c|}{ Total } \\
\hline & $\begin{array}{l}\mathrm{Na} \mathrm{na}^{+} \\
(\mathrm{n}=51)\end{array}$ & $\begin{array}{l}\mathrm{na}^{+} \mathrm{na}^{+} \\
(\mathrm{n}=53)\end{array}$ & $\begin{array}{l}\mathrm{Na} \mathrm{na}+ \\
(\mathrm{n}=54)\end{array}$ & $\begin{array}{l}\mathrm{na}^{+} \mathrm{na}^{+} \\
(\mathrm{n}=53)\end{array}$ & $\mathrm{Na} \mathrm{na}^{+}$ & $\mathrm{na}^{+} \mathrm{na}^{+}$ & $\begin{array}{c}\text { Régime } \\
1\end{array}$ & $\begin{array}{l}\text { Régime } \\
2\end{array}$ \\
\hline \multicolumn{9}{|l|}{ Poids corporel $(\mathrm{g})$ : } \\
\hline $1 \mathrm{j} . \quad \ldots \ldots \ldots \ldots$ & 37,9 & 37,0 & 37,3 & 36,3 & 37,6 & 36,7 & 37,3 & 36,8 \\
\hline $2 \mathrm{~s}$. & 86,9 & 86,1 & 84,3 & 81,3 & 85,6 & 83,7 & 86,4 & 82,9 \\
\hline 4 s. $\ldots \ldots \ldots \ldots$ & 255,5 & 259,3 & 249,2 & 250,1 & 252,3 & 254,7 & 257,1 & 249,6 \\
\hline $6 \mathrm{s.} \ldots \ldots \ldots$ & 529,6 & 508,7 & 537,1 & 537,4 & 533,5 & 523,1 & 518,9 & 537,3 \\
\hline $8 \mathrm{~s} . \ldots \ldots \ldots$ & 866,5 & 818,1 & 831,8 & 878,8 & 848,7 & 848,5 & 841,8 & 855,1 \\
\hline $10 \mathrm{~s} . \ldots \ldots \ldots \ldots$ & 1157,8 & 1123,5 & 1141,7 & 1196,3 & 1149,5 & 1159,9 & 1140,3 & 1168,7 \\
\hline Gain de poids $(g)$ : & & & & & & & & \\
\hline 2- 4 s. $\ldots \ldots \ldots$ & 168,6 & 173,2 & 164,9 & 168,8 & 166,7 & 171,0 & 170,9 & 166,8 \\
\hline 4- 6 s. $\ldots \ldots \ldots \ldots$ & 274,0 & 249,4 & 287,9 & 287,3 & 281,1 & 268,4 & 261,5 & 287,6 \\
\hline $6-8$ s. $\ldots \ldots \ldots \ldots$ & 336,9 & 309,4 & 294,6 & 341,3 & 315,1 & 325,4 & 322,9 & 317,7 \\
\hline $8-10$ s. $\ldots \ldots \ldots$ & 291,3 & 305,4 & 309,3 & 317,5 & 300,6 & 311,5 & 298,5 & 313,4 \\
\hline $\begin{array}{l}\text { Indice } \\
\text { de consommation } \\
\text { (par groupes): }\end{array}$ & & & & & & & & \\
\hline $2-4$ s. $\ldots \ldots \ldots \ldots$ & 2,14 & 2,06 & 2,10 & 2,09 & 2,12 & 2,08 & 2,10 & 2,10 \\
\hline 4- $6 \mathrm{~s} . \ldots \ldots$ & 2,17 & 2,29 & 2,05 & 2,19 & 2,11 & 2,24 & 2,23 & 2,12 \\
\hline $6-8 \mathrm{~s} . \ldots \ldots$ & 2,58 & 2,65 & 2,73 & 2,64 & 2,65 & 2,64 & 2,62 & 2,68 \\
\hline $8-10$ s. $\ldots \ldots \ldots$ & 3,71 & 3,45 & 3,40 & 3,45 & 3,55 & 3,45 & 3,58 & 3,42 \\
\hline Total $2-10 \mathrm{~s} . \ldots \ldots$ & 2,72 & 2,71 & 2,64 & 2,67 & 2,68 & 2,69 & 2,71 & 2,66 \\
\hline $\begin{array}{l}\text { Taux d'acide urique } \\
\text { plasmatique }(\mathrm{mg} / \mathrm{l}) \ldots\end{array}$ & 61,9 & 56,8 & 42,8 & 49,6 & 52,4 & 53,2 & 59,4 & 46,2 \\
\hline
\end{tabular}

L'évolution par âge du poids du plumage en p. 100 du poids vif selon le génotype et le régime, à partir de l'échantillon séparé de coquelets décrit plus haut, figure dans le tableau 6, avec l'analyse de variance qui en est déduite.

Les tableaux 3 et 5 montrent qu'il n'y a d'effet significatif du génotype, chez les poussins mâles en cages, que pour l'indice de consommation de 6 à 8 semaines : celui-ci est meilleur au total pour le génotype «Cou nu » $\mathrm{Na} \mathrm{na}{ }^{+}$. Chez les femelles, et bien qu'un test statistique ne soit pas possible sur ce caractère, dans l'ensemble les différences entre génotypes apparaissent faibles.

Le gain de poids de 4 à 6 semaines est significativement supérieur pour les poulettes $\mathrm{Na} \mathrm{na}{ }^{+}$. Une différence significative existe aussi pour le poids à 1 jour dans ce sexe, sans que l'on puisse l'interpréter pour l'instant. 


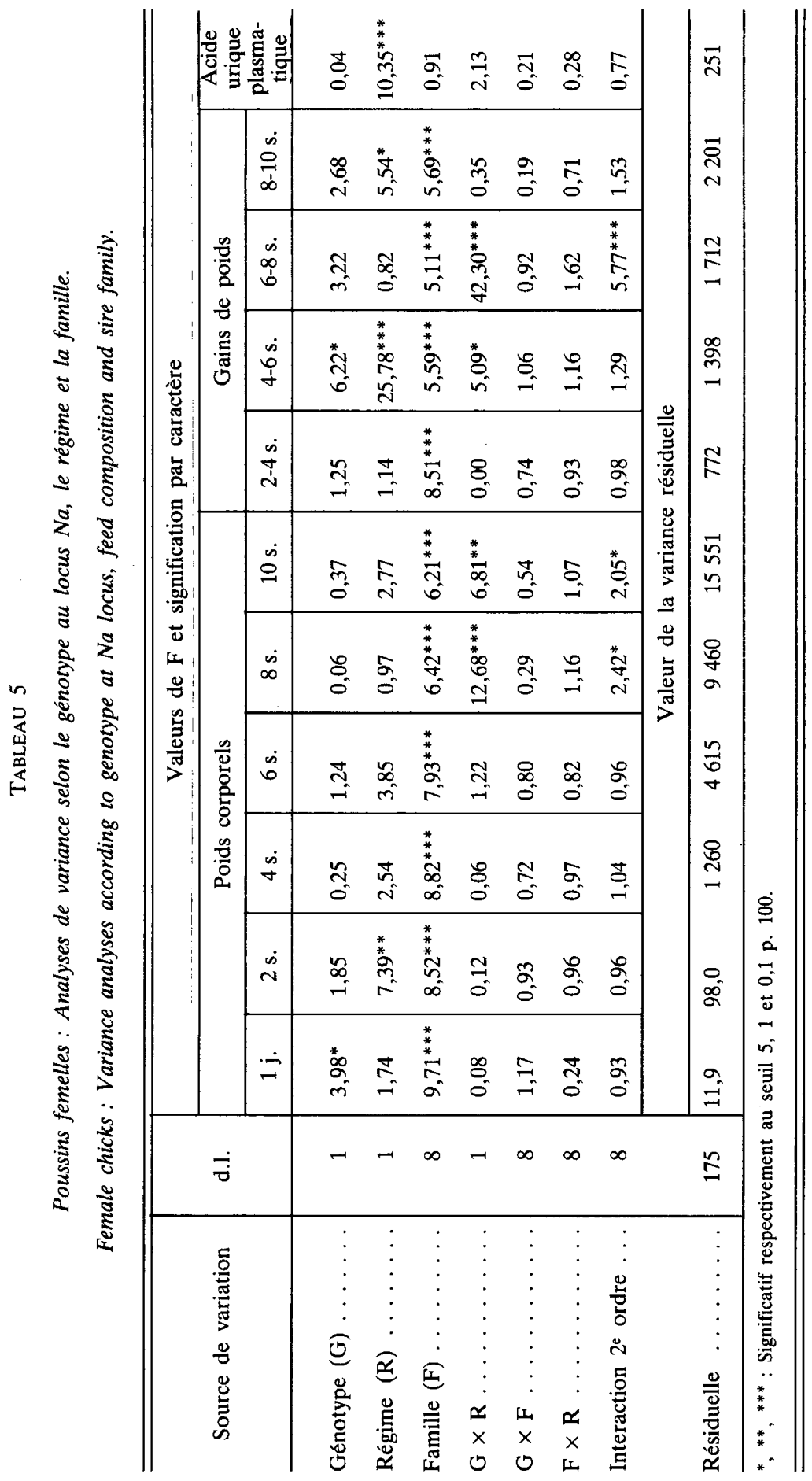




\section{TABLEAU 6}

Poids du plumage en p. 100 du poids corporel par âge, génotype et régime ( $n=64$ au total).

Weight of the plumage in $p .100$ of body weight according to age, genotype and feed composition (in total $n=64$ ).

\begin{tabular}{c|c|c|c|c}
\hline \multirow{2}{*}{ Age (semaines) } & \multicolumn{4}{|c}{ Plumage (p. cent) } \\
\cline { 2 - 5 } & \multicolumn{2}{|c|}{ Régime I } & \multicolumn{2}{c}{ Régime II } \\
\cline { 2 - 5 } & $\mathrm{Na} \mathrm{na}^{+}$ & $\mathrm{na}^{+} \mathrm{na}^{+}$ & $\mathrm{Na} \mathrm{na}^{+}$ & $\mathrm{na}^{+} \mathrm{na}^{+}$ \\
\hline & & & & \\
4 & 3,23 & 3,66 & 3,11 & 4,31 \\
6 & 4,52 & 6,32 & 6,08 & 7,22 \\
8 & 5,76 & 7,04 & 6,60 & 8,36 \\
10 & 7,65 & 9,77 & 7,00 & 8,20 \\
\hline \hline
\end{tabular}

Analyse de variance

\begin{tabular}{|c|c|c|}
\hline Source de variation & d.l. & $\mathbf{F}$ \\
\hline Age (A) $\ldots \ldots \ldots \ldots \ldots \ldots \ldots \ldots \ldots$ & 3 & $64,38^{* * *}$ \\
\hline Régime $(\mathbf{R}) \ldots \ldots \ldots \ldots \ldots \ldots \ldots \ldots \ldots \ldots$ & 1 & 2,53 \\
\hline 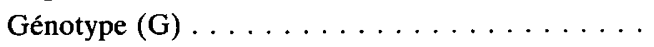 & 1 & $38,42^{* * *}$ \\
\hline 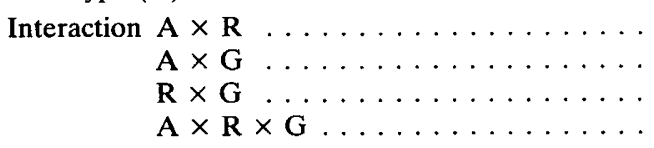 & $\begin{array}{l}3 \\
3 \\
1 \\
3\end{array}$ & $\begin{array}{l}5,12^{* *} \\
2,00 \\
0,30 \\
0,37\end{array}$ \\
\hline Résiduelle $\ldots \ldots \ldots \ldots \ldots \ldots \ldots \ldots \ldots \ldots$ & 49 & \\
\hline
\end{tabular}

${ }^{* *},{ }^{* * *}$ : Significatif respectivement au seuil de 1 et 0,1 p. 100 .

Nous ne commenterons pas plus avant l'effet «famille ", hautement significatif dans la plupart des cas. On note qu'il n'apparaît nulle part d'interaction significative entre famille et génotype, ni entre famille et régime, sauf dans un cas chez les mâles.

Entre génotype et régime, il n'y a pas non plus d'interaction significative chez les mâles. Chez les femelles, et avec la réserve déjà formulée que l'effet « régime " n'est pas séparable d'un éventuel effet " local ", l'analyse en suggère une, hautement significative, pour les poids à 8 et 10 semaines (respectivement $\mathrm{P}<0,001$ et $\mathrm{P}<0,01$ ) et pour les gains de poids de 4 à 6 semaines $(P<0,05)$ et de 6 à 8 semaines $(P<0,001)$. Dans tous les cas, le génotype $\mathrm{Na} \mathrm{na}^{+}$est supérieur au génotype $\mathrm{na}^{+} \mathrm{na}^{+}$en présence du régime le moins riche en protéines (régime 1), alors qu'en présence du régime 2 l'inverse est partout réalisé à l'exception du gain de poids de 4 à 6 semaines pour lequel les génotypes sont presque égaux.

Des tests de signification des différences intrarégime et sexe (non inclus dans les tableaux 2 et 4 ) apportent des précisions complémentaires. Aucune différence entre génotypes dans chaque régime n'est significative chez les mâles. Par contre, chez les 
femelles, en régime 1 le génotype $\mathrm{Na} \mathrm{na}^{+}$est significativement supérieur au génotype normalement emplumé pour les gains de poids de 4 à 6 semaines $(P<0,01)$, de 6 à 8 semaines $(\mathrm{P}<0,01)$ et le poids à 8 semaines $(\mathrm{P}<0,05)$. En régime 2 , c'est le génotype $\mathrm{na}^{+}$na $^{+}$qui est supérieur pour le gain de poids de 6 à 8 semaines $(\mathrm{P}<0,001)$, les poids à 8 et à 10 semaines $(\mathrm{P}<0,05)$. Si l'on observe le sens de toutes les différences entre génotypes "Cou nu » et " normal ", significatives ou non, à partir des tableaux 2 et 4 , on voit qu'à l'intérieur du régime 1 , les mâles «Cou nu » ont dans l'ensemble un léger avantage après l'âge de 6 semaines, tant pour les gains de poids et poids corporels que pour les indices de consommation : cet avantage, exprimé en p. 100 de la valeur moyenne du génotype $\mathrm{na}^{+} \mathrm{na}^{+}$, est de l'ordre de 5 et 4 p. 100 respectivement pour les poids à 8 et 10 semaines, et dépasse 5 p. 100 pour les indices de consommation de 6 à 8 et de 8 à 10 semaines. Chez les femelles, également en présence du régime 1 , l'avantage de croissance du génotype «Cou nu », perceptible à partir de 6 semaines, est maximum à 8 semaines puis s'atténue. Comparativement, avec le régime 2 les différences sont faibles chez les mâles pour les poids corporels mais, comme dans le premier régime, l'indice de consommation du génotype $\mathrm{Na} \mathrm{na}^{+}$est légèrement meilleur à partir de 6 semaines. Pour les femelles, on note un avantage de croissance pondérale du génotype $\mathrm{na}^{+} \mathrm{na}^{+}$. L'effet global du régime apparaît nettement chez les mâles pour les indices de consommation, de 2 à 4 semaines $(P<0,001)$ et de 6 à 8 semaines $(\mathrm{P}<0,05)$ : ces indices sont meilleurs avec la ration la plus riche en protéines. Par contre, cette ration n'améliore pas sensiblement la croissance pondérale, contrairement au cas des femelles, où l'effet du régime est significatif ou hautement significatif, pour les poids à 2 et 6 semaines et les gains de poids de 4 à 6 et de 8 à 10 semaines. Enfin, le taux d'acide urique plasmatique est toujours le plus élevé avec le régime le moins riche en protéines, ce qui peut suggérer dans ce cas une utilisation partielle des protéines à des fins énergétiques.

Le tableau 6 suggère, en ce qui concerne la pousse du plumage, exprimé par rapport au poids vif, que celle-ci est accélérée, après l'âge de 4 semaines, par la ration à 20 p. 100 de protéines. On observe par ailleurs la réduction déjà signalée (BoRDAS et al., 1978 ; MONNET et al., 1979) du poids relatif du plumage par le génotype $\mathrm{Na}$ $\mathrm{na}^{+}$. Cette réduction est sensiblement la même quel que soit le régime : il n'y a pas d'interaction génotype $\mathrm{x}$ régime pour ce caractère.

\section{Discussion et conclusions}

Il est nécessaire au préalable de rappeler les limitations apportées par le dispositif expérimental. Tout d'abord, les résultats sont à traiter de façon strictement séparée dans chaque sexe, ce qui n'exclut pas, cependant, leur comparaison lorsqu'ils présentent des similitudes. En second lieu, chez les femelles, il faut préciser les contraintes apportées par l'absence de répétition. Dans chaque cellule de poussinière, les génotypes sont séparés dans 2 subdivisions symétriques par un simple grillage, de sorte que l'existence d'un effet « local » appréciable confondu avec l'effet « génotype » est peu vraisemblable. Par contre, et bien que les 2 loges correspondant chacune à un régime soient identiques et contiguës, il sera prudent de confirmer des conclusions relatives à l'effet "régime " ou à une interaction "génotype $\mathrm{x}$ régime » par des recherches ultérieures. 
A une température constante de $31^{\circ} \mathrm{C}$, Bordas et al. (1978) et MONNET et al. (1979) avaient observé un avantage de croissance des génotypes $\mathrm{Na} \mathrm{Na}$ et $\mathrm{Na} \mathrm{na}$, l'indice de consommation n'étant pas significativement modifié. Des différences dans le même sens sont trouvées par HANZL \& SoMes (1983) à $38^{\circ} \mathrm{C}$ par comparaison à $21^{\circ} \mathrm{C}$. Dans le cas présent, les températures moins élevées peuvent expliquer que l'avantage associé au génotype «Cou nu » hétérozygote soit plus modeste et souvent non significatif au total. Comme dans les publications citées, quoiqu'à un moindre degré, on pourrait penser à une ingestion alimentaire supérieure permise aux oiseaux «Cou nu » du fait de leur thermolyse accrue mais, sur l'ensemble des 2 régimes, la consommation moyenne par individu diffère peu entre génotypes. Un autre facteur, dans les conditions présentes, peut être le besoin protidique réduit par suite de la moindre production de plumage : il peut mieux apparaître à température élevée, où par ailleurs le "gaspillage " d'énergie par les oiseaux incomplètement emplumés est réduit. Si l'on estime que le plumage représente de 20 à 25 p. 100 du total des protéines corporelles (STURKIE, 1976), sa réduction de l'ordre de 30 p. 100 par le génotype $\mathrm{Na} \mathrm{na}^{+}$pourrait représenter environ 6 à 8 p. 100 de protéines disponibles pour la croissance d'autres tissus à teneur moindre en matière azotée, donc représentant une masse plus grande pour la même quantité de protéines. Un autre article (ZEIN-EL-DEIN et al., 1984) montre que, quels que soient le régime et le sexe, le génotype $\mathrm{Na}^{+} \mathrm{na}^{+}$a un effet favorable sur le pourcentage de muscle dans l'ensemble de la carcasse en fin d'expérience. Ceci pourrait éventuellement refléter l'économie réalisée sur la formation de plumes. Par ailleurs, la mesure de l'excrétion azotée (DELPECH, comm. pers.) ne suggère pas de différence dans l'utilisation de cet élément.

Les suggestions ci-dessus tentent d'expliquer un avantage global associé au gène « Cou nu ». Il resterait à comprendre pourquoi cet avantage se manifeste principalement ou exclusivement en présence du régime à moindre taux protéique ou, en d'autres termes, pourquoi ce régime paraît n'avoir un effet dépressif sur la croissance que chez les poulets normalement emplumés. Compte tenu du fait que la pousse du plumage est modifiée dans la même proportion par le génotype quel que soit le régime, il reste que la quantité totale de protéines disponible pour d'autres parties corporelles peut être un facteur plus limitant pour les poulets entièrement emplumés que pour les «Cou nu » avec une ration relativement pauvre en protéines totales.

$\mathrm{Au}$ total, les présents résultats indiquent qu'un régime relativement pauvre en protéines pourrait être envisagé sans inconvénient apparent pour des poulets «Cou nu », surtout à des températures relativement élevées.

Reçu le 24 octobre 1983.

Accepté le 7 février 1984. 


\section{Références bibliographiques}

Bordas A., Mérat P., Sergent D., Ricard F., 1978. Influence du gène Na (« Cou nu ») sur la croissance, la consommation alimentaire et la composition corporelle du poulet selon la température ambiante. Ann. Génét. Sél. Anim., 10, 209-231.

CRAWFORD R.D., 1976. Incomplete dominance of the gene for naked neck in the domestic fowl. Poult. Sci., 55, 820-822.

HANZl C.J., SOMES R.G.Jr., 1983. The effect of the naked neck gene, $N a$, on growth and carcass composition of broilers raised in two temperatures. Poult. Sci., 62, 934-941.

HuTT F.B., 1949. Genetics of the fowl, 590 pp., McGraw Hill, New York.

MÉRAT P., 1979. Effets associés au gène $\mathrm{Na}$ («Cou nu ») sur le poids corporel et le poids des cufs chez des poules normales et naines. Ann. Génét. Sél. Anim., 11, 127-131.

Monnet L.E., Bordas A., Mérat P., 1979. Gène Cou nu et performances de croissance selon la température chez le poulet. Ann. Génét. Sél. Anim., 11, 397-412.

SCOTT T., CRAWfoRd R.D., 1977. Feather number and distribution in the throat tuft of naked neck chicks. Poult. Sci., 56, 686-688.

SMITH T., LeE R., 1977. A study of the naked neck gene of fowl. Poult. Sci., 56, 1758 (Abstr.).

Sturkie P.D., 1976. Avian Physiology, 3rd ed., 400 pp., Springer Verlag, New York.

Zein-el-Dein A., Ayoub H., Mérat P., 1981. Gène Cou nu et performances de croissance de poulets à deux saisons différentes en Egypte. Ann. Génét. Sél. Anim., 13, 269-280.

Zein-El-Dein A., Mérat P., Bordas A., 1984. Composition corporelle de poulets Cou nu ou normalement emplumés avec deux taux protéiques différents. Génét. Sél. Evol., 16, (4), (sous presse). 